\title{
ACCESS TO EU PUBLIC FINANCIAL SUPPORT AND COMMERCIALIZATION OF INNOVATIONS: EVIDENCE FROM HOSPITALITY INDUSTRIES IN SPAIN AND CROATIA
}

\author{
Nebojša Stojčić
}

https://doi.org/10.20867/tosee.05.1

\begin{abstract}
Purpose - The purpose of this paper is to assess the impact of public financial support to innovations provided through EU funds on success of innovation process in hospitality industries of two leading tourism countries in Europe, Spain and Croatia during 2012-2014 period. The paper investigates whether innovation push channels improve ability of firms to increase share of turnover generated from new products and services. We distinguish between commercialization of innovations which are new to the market and those that are new to the firm but have already been known to other competitors.

Methodology - The study relies on data from the most recent round of Community Innovation Survey, a confidential dataset compiled by Eurostat on innovation activities of firms in EU member states. Treatment analysis is applied to assess whether EU funded public support creates additionality effects or it leads to quiet life behaviour. The model used also introduces number of firm specific characteristics such as previous innovation experience, pattern of innovation development, licensing behaviour, firm size, ownership and the quality of organizational human capital.

Findings - Results of investigation point to the positive impact of EU funds in Spain when it comes to share of sales coming from radical innovations and positive in both countries when it comes to share of sales from innovations which are new to the firm but have been known to the market as well as unchanged or marginally modified products. This signals that in both countries firms exploit EU funds to apply solutions proven successful by others but do not engage in disruptive innovations required for stronger market differentiation and generation of above average returns. The ability to access EU funds for innovations is positively related to firm size and the quality of organizational human capital. Moreover, firms that are part of foreign owned groups have higher chances of accessing EU funds for innovations. Together with previous findings this signals that experience, knowledge transfer and absorptive capacity of firms are the key factors behind the ability of firms to benefit from public support to innovation.

Contribution - In development of innovations firms are often constrained with lack of knowledge, skills and financial resources. Public support is essential in such circumstances for firms that are interested in pursuit of innovations. There is longstanding discussion, however, whether public funds are efficient in facilitating innovation and this debate has particularly been pronounced at EU level. Our study thus provides direct inputs for formulation of future innovation policies that can help to improve performance of firms in hospitality industries.
\end{abstract}

Keywords hospitality industry; EU funds, innovation commercialization, treatment analysis 
ToSEE - Tourism in Southern and Eastern Europe, Vol. 5, pp. 667-677, 2019

N. Stojčić: ACCESS TO EU PUBLIC FINANCIAL SUPPORT AND COMMERCIALIZATION OF ...

\section{INTRODUCTION}

Ever since Schumpeter (1942) economists have explored the pathways for generation of new ideas and the determinants of their market success. With rise in living standards, decrease in costs of travel and advancements in information and communication technologies the intensity of competition has spawned across virtually all economic activities. To become and remain competitive has become a synonym with the ability to continuously generate new ideas that are capable to stand the test of market. Among factors that facilitate or inhibit innovation the question of public support stands as particularly interesting one. Many of revolutionary products that we know today have their origin in public incentives to innovation. Even in those cases where the development of innovations was born by private firms, public support had non-negligible role in overcoming of the financial and other barriers to innovation.

The objective of this paper is to explore the role of the public financial support from European Union funds to the commercialization of innovation activities in hospitality industries of two countries with large tourism sector Croatia and Spain. For many years, innovation literature was concerned with manufacturing sector but in recent years studies have started to acknowledge the rising importance of services in global economic flows and contribution of innovations to their performance and competitiveness. Our study utilizes data obtained from the most recent round of Community Innovation Survey (2012 - 2014), a bi annual survey of firm innovation activities across number of EU member states and candidate countries. The richness of data allows us to assess the impact of EU funds on commercialization of different types of innovations, those that are new to the market and those that are new to the firm only.

The paper is structured as follows. Next section sets theoretical framework and reviews relevant literature in the field. We build this part of paper around two pillars, namely the rationale for public support to innovation activities of firms and the importance of innovations in hospitality industry. Empirical strategy and data are discussed in section three. Section four brings discussion of findings while concluding remarks are contained in the last section.

\section{CONCEPTUAL FRAMEWORK}

\subsection{Public support to innovations}

Generation of innovations is often constrained with relevant resources such as skilled human capital, information and finance (Annique Un and Montoro-Sanchez, 2010). To overcome these barriers to innovation, companies can rely either on private or public funding sources. The provision of public support to innovation takes many forms ranging from public financial support through supply - side or "push" incentives to public procurement for innovation and other demand side incentives. In Europe, such incentives are provided by local and regional, national and supranational entities such as European Union (EU) funding agencies for innovation, science and regional development. However, despite large consensus over need for public investment in innovation the impact of these measures remains far from obvious. Hashi and Stojcic (2013), for 
ToSEE - Tourism in Southern and Eastern Europe, Vol. 5, pp. 667-677, 2019

N. Stojčić: ACCESS TO EU PUBLIC FINANCIAL SUPPORT AND COMMERCIALIZATION OF ...

example, find that firms with access to public finance have less success in transformation of their innovation efforts into products and services accepted by the market.

Annique Un and Montoro - Sanchez (2010) find different sources of public funding including local, regional authorities, university grants and state enterprises to increase propensity of firms to innovate in Spain. Among these, EU funding sources stand as key determinant of innovations in products, goods and services among service sector firms. Czarnitzki and Lopes-Bento (2014) find that both national and EU sources of public finance for innovation increase propensity of German firms to innovate as well as their sales of products which are new to the firm and new to the market but the national programmes seem to be more efficient than EU funded ones. Fernandez-Ribas (2009) find that national public programmes increase propensity of firms to introduce product and process innovations while supranational (EU) ones are associated with additionality in terms of sales from incremental innovations.

The above findings suggest that public support from innovation may exert adverse impact on innovation outcomes subject to level of government from which it originates. As Fernandez-Ribas (2009) note, the specific characteristics of innovation process determine the effectiveness of particular public funding sources. According to their view, public intervention of upper-level governments (national and supranational, e.g. EU) may be desirable when innovations generate cross-border externalities, if they require threshold amount of resources for projects to be viable and efficient and when parts of research process cannot be easily divided. On the other hand, local and regional public intervention in innovation system may be more desirable when innovation process is sensitive to specificities of local innovation system and when they need to be tailored to local conditions.

Romero-Martinez et al. (2010) find that service sector small and medium sized (SME) firms have higher probability of using EU funding. The EU funding contributes to the introduction of product and process innovation as well as the management systems and organization of work innovations. However, the study finds that only small portion of firms actually do use such funds and that majority of financing for innovations comes from national and particularly local/regional levels. What all these findings signal is that, on the whole, public support creates additionality effects in service sector and that these effects differ with respect to characteristics of innovation process. However, to the best of our knowledge, studies on service sector innovations treat this sector as a whole thus omitting its heterogeneity. There is evident shortage of studies on public support to innovations in sectors such as hospitality industries and our study aims to fill this gap.

\subsection{Innovations in hospitality industry}

Hospitality industry is commonly defined as a pool of business activities aimed at meeting of leisurely needs in terms of accommodation, food and transportation. It is characterized with aim to maximise customer satisfaction through provision of high level services. Like all aspects of tourism it has number of additional distinctive features. These are commonly grouped around simultaneity of production and consumption and the mobility of markets. The ability to compete in such setting is closely related to innovation activities of firms. Through innovations hospitality firms can improve quality 
ToSEE - Tourism in Southern and Eastern Europe, Vol. 5, pp. 667-677, 2019

N. Stojčić: ACCESS TO EU PUBLIC FINANCIAL SUPPORT AND COMMERCIALIZATION OF ...

of their services, increase efficiency, provide a tailored experience to their end users and ultimately outperform their rivals (Chang et al., 2011).Not all such efforts, however, are successful and they often fail as a result of barriers such as knowledge, finance or skills.

The innovation process in hospitality industries and in tourism in general has been addressed from number of perspectives. Hjalager (2010) defines three broad categories of determinants of innovation in tourism sector. On the one hand, the entrepreneurial activity, analogous to Schumpeterian portray of innovation, is a principal driving force of innovation in tourism like in many other activities. Yet, the impulses to birth of novel ideas may come from both supply and demand side. Indeed, market demand seems to play far larger role in innovations of hospitality industry. Stamboulis and Skayannis (2003) note that demand side impulses are single most important driving force of innovation in all tourism industries. To this end, lead users are identified as those that provide direction for future development of industry.

The concept of innovation systems has recently attracted significant attention of both academics and policy makers. Provision of knowledge through inter-firm relations as well as intra-group knowledge flows between domestic and foreign affiliates seem to matter for ability of firms to overcome conventional barriers to innovation such as lack of skills, knowledge and technology but also financial ones. Localized knowledge sources play particularly important role in such framework. Destinations possess certain characteristics and competences that may provide fertile soil for innovations to flourish. These may include knowledge embodied in other firms, locational comparative advantages but also collaboration with science institutions and universities.

Apart from these generic determinants of innovation, existing research identified several other determinants specific to hospitality industry. Existence of locational advantages, innovation systems and critical mass of entrepreneurial activity may serve as a starting point but it is absorptive capacity of firms and the activities of their employees that determine whether this potential will transform into generation of novel ideas and subsequently new competitive advantage. Hence, strategic approach to management of human capital is of crucial importance for the success of innovation process (Ottenbacher et al., 2006).

The discussion so far suggests that in development of innovations companies in hospitality industry rely on mixture of internal capabilities and external sources. The two may act as complements or offset each other. Since the seminal work of Cohen and Levinthal (1990) it has been brought to attention of research community that the ability of firms to adopt external knowledge and turn it into competitive advantage depends on their absorptive capacity. Zahra and George (2002) propose four types of such capabilities defined as the ability to identify and acquire knowledge, ability to interpret or assimilate knowledge in strategic way, the ability to transform acquired knowledge and to align it with existing knowledge and finally the capacity to use acquired, assimilated and transformed knowledge to develop innovations. 
ToSEE - Tourism in Southern and Eastern Europe, Vol. 5, pp. 667-677, 2019

N. Stojčić: ACCESS TO EU PUBLIC FINANCIAL SUPPORT AND COMMERCIALIZATION OF ...

The determinants of innovation in hospitality industry have been empirically assessed in number of studies. Guisado-Gonzalez et al. (2013) show that in hospitality industries in Spain the innovation strategies most commonly combined are the acquisition of external technology services and machinery and R\&D cooperation. Martinez-Ros and OrfilaSintes (2009) report as determinants of incremental and radical innovation the type of hotel management, market strategy, firm size and location. Lopez-Fernandez et al. (2011) identify four factors that encourage innovation in hospitality industry defined as firm size, membership of a group, organizational structure and openness towards changes. However, study did not find any effect of public financial support to innovations in hospitality industry.

Orfilla-Sintes and Mattsson (2009) find positive effect of firm size, provision of complementary services, management of human capital and demand side impulses such as previously mentioned lead users on different types of firm innovations in hospitality industry. Pivcevic and Garbin Pranicevic (2012) explored innovation activity in Croatian hotel sector. The overall finding of study is moderate intensity of innovation among surveyed firms. Unlike previously mentioned findings, this study finds that Croatian hotel sector firms do not innovate in terms of technological innovations but rather implement existing technological solutions, a pattern that is sometimes labeled as imitation or even incremental, new to the firm, innovation.

Everything said in this section offers several stylized facts relevant for continuation of our analysis. It is evident that market failures provide rational for public support to innovation but empirical findings on this link have been ambiguous so far. In hospitality sector, innovations stand as important prerequisite of the ability to compete in conditions of intensifying global competition and technological advancements that remove geographical barriers to travelling. Existing research has identified number of determinants of innovation in hospitality industry. We now know that locational factors, innovation systems and demand incentives provide impulses to innovation activities of firms but it is indigenous management of human capital that determines the ability of firms to exploit this competitive potential. The role of public support in this process has been investigated to lesser extent and our study aims to fill this gap.

\section{EMPIRICAL STRATEGY AND DATA}

Our empirical strategy aims to determine the role of public support in commercialization of innovations developed by firms in hospitality industry of two leading European tourism countries, Spain and Croatia. In terms of innovativeness, existing literature commonly distinguishes between two patterns of innovations defined as radical and incremental innovations. The former refers to those activities embedded with knowledge which is new to both firm and the market and often present significant departure from existing practices of organization. They emerge as solutions to the most important challenges of both organization and sector and as such possess great potential for differentiation and above average returns. Incremental innovations, on the other hand, refer to activities which take form of either marginal improvements in existing products, services and procedures or introduction of activities which are new to the firm but have been known to the market. 
ToSEE - Tourism in Southern and Eastern Europe, Vol. 5, pp. 667-677, 2019

N. Stojčić: ACCESS TO EU PUBLIC FINANCIAL SUPPORT AND COMMERCIALIZATION OF ...

The innovation activity of firms is measured in number of ways. The most common practice is to include dichotomous indicator of the introduction of certain type of innovation by firm. Equally popular measure of innovations is the extent of investment in research and development. However, the ultimate outcome and final criterion of success of innovation is its acceptance by the market. Existing studies, partly due to lack of data, have devoted limited attention to this dimension of innovation process. Our study, however, extends existing literature in this aspect. Specifically, we focus on the ability of firms from hospitality sector to generate higher share of revenues from products and services that are considered innovative. In doing this, we distinguish between three categories defined as share of revenues coming from products and services new to the market or radical innovations, share of revenues coming from innovations that are new only to the firm and can be considered as incremental innovations and overall share of revenues that come from products and services that are new to either firm or market.

Our principal matter of analysis is the role of public support in success of innovation process defined as above. To explore this we employ rich dataset collected through Eurostat's Community Innovation Survey, a biannual survey of innovation activities of European enterprises and one of most comprehensive sources of information on firm innovative behavior in EU member states. The analysis utilizes the most recent 20122014 version of this dataset containing information on firm behavior in hospitality industries in Croatia and Spain. Surveyed firms were asked about their innovation and business activities over 2012-2014 period. The richness of dataset reflects itself in number of variables relevant for our investigation. To this end, respondents have to declare whether they received support for innovation activities from local, national and EU funded public sources. Hence, our key variable of interest is dichotomous variable that takes value of 1 if firm received public support for innovation from EU funded sources.

Empirical strategy suitable for such analysis is treatment analysis, an econometric technique frequently used to measure effects of particular policies, activities or processes on selected outcomes such as commercialization of innovations. Typically, treatment techniques are divided into regression-based techniques and matching approaches. Our analysis employs regression-based inverse probability weighted regression adjustment (IPWRA) approach which models the outcome and treatment in a way that accounts for non-random treatment assignment. Moreover, IPWRA estimators are known as doublerobust since they rely on two models, one for prediction of the treatment status and another for prediction of the outcomes. Such double-robust property requires correct specification of only one of the two models for derivation of consistent estimates. The output of such analysis may be assessed in terms of average treatment across the population (ATE) or the average treatment effects on the subset of treated subjects (ATET). In general form the model of investigation can be defined as:

Innovation $_{i}=$ cons $+a *$ EUfunds $_{i}+\sum_{j=1}^{n} \beta_{j} X_{j}+u_{i}$

where Innovation $_{i}$ stands for share of turnover generated by products which are either new to the market only, firm only or to both firm and market. EUfunds $s_{i}$ is a binary variable that takes value of 1 if firm received public support to innovation from EU funds while $\mathrm{X}$ encompasses the set of explanatory variables. These include two dummy 
ToSEE - Tourism in Southern and Eastern Europe, Vol. 5, pp. 667-677, 2019

N. Stojčić: ACCESS TO EU PUBLIC FINANCIAL SUPPORT AND COMMERCIALIZATION OF ...

variables for firm size, a dummy variable for firms that are part of a business group in order to capture intra-firm knowledge flows, introduction of organizational and marketing innovations and previous innovation experience as well as dummy variable for human capital of the firm and cooperation with external entities in development of innovations. Table 1 provides description of variables.

\section{Table 1: Description of variables}

\begin{tabular}{|l|l|}
\hline Variable & Description \\
\hline turnun & $\begin{array}{l}\text { Share of revenues from unchanged or marginally modified products and } \\
\text { services (in \%) }\end{array}$ \\
\hline turnin & Share of revenues from products and services new to the firm (in\%) \\
\hline turnmar & Share of revenues from products and services new to the market (in \%) \\
\hline small & 1 if firm with less than 50 employees \\
\hline medium & 1 if firm with more than 50 and less than 250 employees \\
\hline large & 1 if firm with more than 250 employees (base category) \\
\hline orginno & $\begin{array}{l}1 \text { if firm introduced any form of organizational innovation (new business } \\
\text { practices, organization of work responsibilities and organization of external } \\
\text { relations) }\end{array}$ \\
\hline mktinno & $\begin{array}{l}1 \text { if firm introduced any form of marketing innovation (new promotion } \\
\text { techniques, new sales channels, new pricing methods) }\end{array}$ \\
\hline inaba & 1 if firm had previous experience of ongoing or abandoned innovations \\
\hline group & 1 if firm is part of an enterprise group \\
\hline coop & $\begin{array}{l}1 \text { if firm cooperated in development of innovations with external entities (other } \\
\text { firms, professional and research institutions, universities etc.) }\end{array}$ \\
\hline hcap & 1 if firm employs more than 25\% of staff with tertiary degree \\
\hline
\end{tabular}

\section{DISCUSSION OF FINDINGS}

\subsection{Probability of receiving $E U$ financial support for innovations}

We begin our analysis by looking into determinants of probability to obtain financial support for innovations from EU bodies. All results are obtained with use of Stata 15 software. Table 2 presents results of probit analysis where the dependent variable takes value of 1 if firm received EU funds and 0 otherwise. It needs to be said that throughout both samples only small portion of firms had success in acquiring such support. In Croatia, for instance, out of 231 surveyed firms only about $7 \%$ have declared that they received financial assistance for development of innovations. In Spain, the number of EU supported innovators in hospitality sector is even lower. Out of 1046 firms only $1.5 \%$ have reported receipt of EU sourced support for innovations. 
ToSEE - Tourism in Southern and Eastern Europe, Vol. 5, pp. 667-677, 2019 N. Stojčić: ACCESS TO EU PUBLIC FINANCIAL SUPPORT AND COMMERCIALIZATION OF ...

Table 2: Results of selection equation (dep.var: Probability of receiving EU financial support for innovations)

\begin{tabular}{|l|l|l|}
\hline & Croatia & Spain \\
\hline small & $-0.91 * *$ & -0.69 \\
\hline medium & -0.50 & 0.07 \\
\hline orginno & $0.80 *$ & -0.06 \\
\hline mktinno & -0.25 & 0.39 \\
\hline inaba & $0.79 * *$ & $0.82 * *$ \\
\hline group & 0.33 & 0.08 \\
\hline coop & $0.67 *$ & $1.72 * * *$ \\
\hline hcap & $0.56 *$ & $0.51 * *$ \\
\hline LR test & $49 * * *$ & $97 * * *$ \\
\hline Observations & 231 & 1046 \\
\hline
\end{tabular}

$* * *, * *$ and $*$ denote significance at $1 \%, 5 \%$ and $10 \%$ levels of significance. Detailed printouts available upon request

The results of analysis reveal rather coherent story. In Croatia, the probability of receiving EU financial support seems to be related to organizational capacities and resources. Several findings motivate such statement. First, smaller firms have lower probability of winning EU funds. Secondly, firms that introduce organizational innovations are more likely to be successful in reaching such financial resources. The probability of winning financial funds for innovation increases if firms had previous experience with innovations and if they cooperated with other firms, universities or professional and research bodies in development of innovations. Finally, higher level of human capital increases the probability of winning EU funds. Together, these findings suggest that it is absorptive capacity and internal resources what matters for access to EU funds. Whether such funds are put in efficient use is the question that will be answered in section 4.2.

\subsection{The impact of EU funds on commercialization of innovations}

The final success of innovations is determined through their reception by market. For this reason, as a final part of investigation we turn to the ability of firms to generate revenues related to innovations. Specifically, we decompose total revenues of firms in three categories, the proportion of revenues coming from unchanged or marginally modified products, revenues coming from incremental innovations which are new to the firm but have been known for some time to the market and thus can be classified as imitation and revenues coming from products and services new to the market. As noted previously we use inverse probability weighted regression adjustment (IPWRA) approach. Results of analysis are presented in Table 3 below. 
ToSEE - Tourism in Southern and Eastern Europe, Vol. 5, pp. 667-677, 2019 N. Stojčić: ACCESS TO EU PUBLIC FINANCIAL SUPPORT AND COMMERCIALIZATION OF ...

Table 3: The impact of EU financial support on commercialization of innovations

\begin{tabular}{|l|c|c|c|c|}
\hline & \multicolumn{2}{|c|}{ Croatia } & \multicolumn{2}{c|}{ Spain } \\
\hline & ATE & ATET & ATE & ATET \\
\hline $\begin{array}{l}\text { Revenues from unchanged or marginally } \\
\text { modified products }\end{array}$ & $67.84 * * *$ & $27.89 * * *$ & $19.73 * * *$ & 1.12 \\
\hline $\begin{array}{l}\text { Revenues from incremental innovations } \\
\text { new to the firm }\end{array}$ & $18.72 * * *$ & $17.81 * * *$ & $21.50 * * *$ & $9.85 * * *$ \\
\hline $\begin{array}{l}\text { Revenues from innovations new to the } \\
\text { market }\end{array}$ & 2.33 & 4.31 & $54.37 * * *$ & $19.46 * * *$ \\
\hline $\begin{array}{l}\text { Overidentification test } \\
\text { Ho: Covariates are balanced }\end{array}$ & \multicolumn{2}{|c|}{0.5916} & & 0.3579 \\
\hline Number of observations & \multicolumn{2}{|c|}{231} & & 1046 \\
\hline
\end{tabular}

$* * *, * *$ and $*$ denote significance at $1 \%, 5 \%$ and $10 \%$ levels of significance. Detailed printouts available upon request

Results of investigation in Table 3 are divided in two categories. Left columns for both countries present average treatment effects (ATE) vs firms that did not receive EU financial support. Right columns present average treatment effects on treated (ATET), i.e. the difference exercised by recipient firms themselves as a result of financial support for innovations. Findings from Table 3 suggest divergent effects of financial incentives on success of innovation process across two countries. In Croatian hospitality industry we obtain positive impact on shares of revenues from unchanged or marginally modified products and services and from innovations new to the firm. The coefficient on radical, new to the market, innovations is not statistically significant. The magnitude of coefficients suggests that Croatian firms use EU funds predominantly for marginal improvements in existing products and to lesser extent for acquisition of knowledge created elsewhere, e.g. implementation of ideas that are new to the firm but have been known to the market for a long time. Such pattern is typical for firms that take position of followers and mimic actions of leading rivals.

Results for Spanish sample offer different story. We find positive coefficients for all three segments of revenues. However, the magnitude of coefficients signals that smallest gains are in those segments of firm performance related to the existing or marginally modified products. Firms that introduce innovations that are new to the firm, and particularly those firms whose products new to the market exercise strong additionality effects from EU public funds for innovation. It is also interesting to reflect on ATET effects. These effects are several times smaller than ATE ones. Such finding signals that additionality from EU funds comes to firms which already possess supreme resources and further increases their excellence.

How can all of these findings be interpreted? Our analysis of section 4.1 demonstrated that it is organizational resources and absorptive capacity what matters for the ability of firms to appropriate EU funds. It is thus very likely that the lack of these resources in Croatia is behind sluggish innovation additionality effects of public financial support. Spanish findings are more in line with expectations about the direction and destination of funds used to publicly support innovation efforts of firms. Nevertheless, both findings support policy rationale for provision of public support to innovation and signal that such activities have to be complemented with those in other areas of innovation ecosystem. 
ToSEE - Tourism in Southern and Eastern Europe, Vol. 5, pp. 667-677, 2019

N. Stojčić: ACCESS TO EU PUBLIC FINANCIAL SUPPORT AND COMMERCIALIZATION OF ...

\section{CONCLUSION}

There is a long standing debate on the justification of public support to innovation efforts of firms. Contrary to traditional stance about minimalist government intervention in market processes, nowadays there is plentiful of evidence that some of the greatest innovations of our time would not see the light of the day without public support. The constraints faced by many firms, particularly small and medium sized ones are another reason why the demand for innovation oriented public policies is growing in recent years. Many countries are in shortage of funds required to support innovation for which reason supranational sources of financing such as EU funds have an important role. The formulation of such policies shall require strong and empirically founded pillars which are currently scarce and mostly confined to industries within manufacturing sector. This paper attempted to enrich existing body of knowledge by assessing the impact of financial support to innovation through European Union's funds in hospitality industries of Croatia and Spain, two countries among European leaders in tourism sector.

The results of our investigation provide support to policies intended to stimulate and facilitate innovation activities of firms from hospitality industry. However, effects in Croatia suggest that such measures can fall short to optimum if they are not accompanied with measures intended to strengthen absorptive capacity of companies. While Spanish firms use EU funds to generate additionality effects in terms of products and services genuinely new to the market, in Croatia the use of such funds seems to be related to imitation and incremental changes in existing business practices. Future policies should adopt multidimensional approach that would not only provide firms with resources relevant for development and commercialization of innovations but more importantly build their competences and capabilities for indigenous flourishing of creativity and its transformation into innovation-based competitive advantages.

Future research should address the above issues if limitations met in our work such as lack of relevant data will be met. It would be also worth establishing longitudinal database of innovation activities of firms for European countries that would bear information similar to ones contained in Community Innovation Survey. Addressing these shortcomings would broaden our understanding of firm innovation activities.

\section{REFERENCES}

Annique Un, C. and Montoro-Sanchez, A. (2010), "Public funding for product, process and organisational innovation in service industries", The Service Industries Journal, 30(1), pp. 133-147, DOI:10.1080/02642060802252035.

Cohen, W.M. and Levinthal, D.A. (1990), "Absorptive capacity: A new perspective on learning and innovation". Administrative Science Quarterly, 35(1), pp. 128-152.

Czarnitzki, D. and Lopes-Bento, C. (2014), "Innovation Subsidies: Does the Funding Source Matter for Innovation Intensity and Performance? Empirical Evidence from Germany”, Industry and Innovation, 21(5), pp. 380-409, DOI: 10.1080/13662716.2014.973246

Fernandez-Ribas, A. (2009), "Public support to private innovation in multi-level governance systems: an empirical investigation", Science and Public Policy, 36(6), pp. 457-467, DOI: $10.3152 / 030234209 X 460953$.

Guisado-González, M., Guisado-Tato, M. and Sandoval-Pérez, A. (2013), "Determinants of innovation performance in Spanish hospitality companies: analysis of the coexistence of innovation strategies", The Service Industries Journal, 33(6), pp. 580-593, DOI:10.1080/02642069.2011.614343 
ToSEE - Tourism in Southern and Eastern Europe, Vol. 5, pp. 667-677, 2019

N. Stojčić: ACCESS TO EU PUBLIC FINANCIAL SUPPORT AND COMMERCIALIZATION OF ...

Hashi, I. and Stojcic, N. (2013), "The impact of innovation activities on firm performance using a multi-stage model: Evidence from the Community Innovation Survey 4", Research Policy, 42(2), pp. 353-366.

Hjalager, A.M. (2010), “A review of innovation in tourism”, Tourism Management, 31(1), pp. 1-12.

López-Fernández, M.C, Serrano-Bedia, A.M. and Gómez-López, R. (2011), "Factors Encouraging Innovation in Spanish Hospitality Firms", Cornell Hospitality Quarterly. 52(2), pp. 144-152. DOI: $10.1177 / 1938965510393723$

Martinez-Ros, E. and Orfila-Sintes, F. (2009), "Innovation activity in the hotel industry", Technovation, 29(8), pp. 632-641.

Orfila-Sintes, F. and Mattsson, J. (2009), "Innovation behavior in the hotel industry", Omega. 37, pp. 380-394.

Ottenbacher, M., Shaw, V. and Lockwood, A. (2006), "An investigation of the factors affecting innovation performance in chain and independent hotels", Journal of Quality Assurance in Hospitality and Tourism, 6(3-4), pp. 113-128, DOI: 10.1300/J162v06n03 07

Pivcevic, S. and Garbin Pranicevic, D. (2012), "Innovation activity in the hotel sector - the case of Croatia", Economic Research, 25(1), pp. 337-363.

Romero-Martínez, A., Ortiz-de-Urbina-Criado, M. and Ribeiro Soriano, D. (2010), "Evaluating European Union support for innovation in Spanish small and medium enterprises", The Service Industries Journal, 30(5), pp. 671-683, DOI: 10.1080/02642060802253868

Stamboulis, Y., and Skayannis, P. (2003), "Innovation strategies and technology for experience-based tourism", Tourism Management, 24(1), pp. 35-43.

Zahra, S.A. and George, G. (2002), "Absorptive capacity: A review, reconceptualization, and extension", Academy of Management Review, 27(2), pp. 185-203.

Nebojša Stojčić, PhD, Associate Professor

University of Dubrovnik

Department of Economics and Business Economics

Lapadska obala 7, Dubrovnik, Croatia

Phone: +385981621005

E-mail: nstojcic@unidu.hr 